\title{
POR UMA CRÍTICA ARTÍSTICA
}

\author{
GABRIEL MOREIRA FAULHABER ${ }^{1}$
}

Universidade Federal de Juiz de Fora

Programa de Pós-Graduação em Letras - Estudos Literários.

Rua José Lourenço Kelmer, s/n - 36036-330 - Juiz de Fora (MG) - Brasil

gabrielblake@hotmail.com.br

Resumo. O presente artigo intenta propor uma nova prática de crítica literária. Partindo de um diagnóstico feito por Alberto Pucheu (2007) de que a crítica literária estaria, há algum tempo, completamente afastada de seu objeto de estudo, movimentamos nomes como Nietzsche, Barthes e Deleuze para apresentarmos uma possibilidade de crítica que, em seu próprio fazer, ofereça marcas e características de seu objeto abordado. Uma crítica artística.

Palavras-chave: critica; leitor; arte.

\begin{abstract}
This paper intends to propose a new practice of literary criticism. Starting from a diagnosis elaborated by Alberto Pucheu that literary criticism would have been, for some time, completely aloof from its object of study, we rummage names like Nietzsche, Barthes and Deleuze to present a possibility of criticism that, in its own doing, offers traces and characteristics of its approached object. An artistic criticism.
\end{abstract}

Keywords: criticism; reader; art.

\section{INTRODUÇÃO}

Sempre se discutiu acerca do valor da literatura e do fazer literário - quais seriam suas funções e especificidades. Ao longo dos tempos, desde a Grécia, chegando à contemporaneidade, tivemos as mais diversas explicações e abordagens. Neste texto, separaremos, primeiramente, duas delas para, posteriormente, iniciarmos nossa reflexão.

Em suas Seis propostas para o próximo milênio, que funcionam como direcionamentos gerais para obras do presente e do futuro, Italo Calvino se propõe a elucidar as características singulares e os valores particulares, destacando seis traços que considera essenciais para a constituição de uma obra literária forte no período mencionado. São eles: leveza, rapidez, exatidão, visibilidade, multiplicidade e consistência. Utilizaremos em nossa abordagem as duas primeiras por considerá-las as que mais compartilham semelhanças, além de serem as mais encantadoras em nossa opinião.

Para desenvolver sua concepção de "leveza", o escritor italiano evoca, entre outras imagens, o mito de Perseu.

\footnotetext{
${ }^{1}$ Doutorando em Letras (Estudos Literários) pela Universidade Federal de Juiz de Fora.
} 
O único herói capaz de decepar a cabeça da Medusa é Perseu, que voa com sandálias aladas; [...] Para decepar a cabeça da Medusa sem se deixar petrificar, Perseu se sustenta sobre o que há de mais leve, as nuvens e o vento; e dirige o olhar para aquilo que só pode se revelar por uma visão indireta, por uma imagem capturada no espelho. [...] É sempre na recusa da visão direta que reside a força de Perseu, mas não na recusa da realidade do mundo de monstros entre os quais estava destinado a viver. (CALVINO, 1990, p. 18-19)

Vemos que não se trata de uma fuga do que é corpóreo, de um escapismo ou evasão, mas de uma mudança de ótica, um cuidado para não se petrificar, um olhar através de outros meios.

A partir dessa concepção, Calvino vai ressaltar a importância da leveza na composição de um texto como "algo que se cria no processo de escrever" (CALVINO, 1990, p. 24), algo que se faz no exercício e experiência de escrita, anulando seu peso, evitando sua força esmagadora e dissolvendo as paralisantes hierarquias. Assim como o olhar de Perseu para o reflexo, não se trata de uma questão de negação do peso, da corporeidade, do trabalho, do rigor, mas a afirmação de uma busca em prol de outro nível de percepção que é valorizada. Uma busca ativadora de forças e potencialidades que se deslocam ao encontro de novos meios de conhecimento, existência e atuação. Um esquivar-se de um peso estabelecido: proposta de uma linguagem que descarrega, aliviando o corpo e abrindo caminho para a criação de possibilidades.

Se quisesse escolher um escolher um símbolo votivo para saudar o novo milênio, escolheria este: o salto ágil e imprevisto do poeta-filósofo que sobreleva o peso do mundo, demonstrando que sua gravidade detém o segredo da leveza. (CALVINO, 1990, p. 26)

Ao terminarmos o conceito de "leveza" e chegarmos, dentre as seis propostas, à "rapidez", encontramos três elementos que a acompanham para que ela funcione: economia ritmo e lógica. Indissociáveis, eles agem a favor de uma comunicabilidade que não seja temporária e passageira - importante não confundir rapidez com efemeridade -, mas que se perpetue através de ressonâncias. O autor de Cidades Invisíveis utiliza outra imagem de origem mitológica para demonstrar seu pensamento, recorrendo a Mecúrio, deus mensageiro, dotado de habilidade e agilidade e a Vulcano, deus ferreiro, que não transita através dos ares, ficando entocado fabricando objetos valiosos e armas para deuses e heróis. Ao martelo forjador de um, se junta a leveza célere de outro.

A mobilidade e agilidade de Mercúrio são as condições necessárias para que as fainas intermináveis de Vulcano se tornem portadoras de significado, e ganga mineral informe assumam forma os atributos divinos, cetros ou tridentes, lanças ou diademas. O trabalho do escritor deve levar em conta: o tempo de Mercúrio e o tempo de Vulcano, uma mensagem de imediatismo obtida à força de pacientes e minuciosos ajustamentos; uma intuição instantânea que apenas formulada adquire caráter definitivo daquilo que não poderia ser de outra forma; mas igualmente o tempo que flui sem outro intento que pode deixar as ideias e sentimentos se sedimentarem, amadurecerem, libertarem-se de toda impaciência e de toda contingência efêmera. (CALVINO, 1990, p. 6869) 
Ao contrário do que se pensa, quando se evoca a palavra rapidez - da mesma forma como acontece com leveza -, não temos descartados o rigor e o trabalho, é a partir do esforço, paciência e ajustamentos que se consegue um efeito de imediatismo. Percebemos uma atuação em complementaridade: só se atinge a velocidade pretendida, compreendendo e atravessando todo um processo que não vise uma efemeridade, mas uma duração e extensão.

Como destacamos no início de nosso texto, compreendemos esses dois aspectos apontados por Calvino - leveza e rapidez - como os que mais compartilham similaridades dentre suas seis propostas. O próprio autor nos dá uma pista: "a leveza para mim está associada à precisão e à determinação, nunca ao que vago e aleatório" (CALVINO, 1990, p. 30). Levaremos em conta, portanto, leveza e rapidez atuando em consonância e usaremos uma palavra composta pelas duas como um termo único para nos referimos a elas. Agora, antes de entrarmos em nossa discussão - a prática do que seria uma crítica artística -, consideramos mais um apontamento e chamaremos outra voz em nosso auxílio para que possamos ter uma melhor compreensão daquilo que estamos tratando como força da literatura.

Em sua Aula Inaugural no Collège de France, Antoine Compagnon se questiona sobre o porquê de se estudar/lecionar literatura nos dias atuais e sobre a validade do discurso literário em nosso tempo, reconhecendo o seguinte cenário.

Há muito tempo ela [a literatura] não é mais a única a reclamar para si a faculdade de dar uma forma à experiência humana. $\mathrm{O}$ cinema $\mathrm{e}$ diferentes mídias, ultimamente consideradas menos dignas, têm uma capacidade comparável de fazer viver. (COMPAGNON, 2009, p. 57)

Para fazer a defesa da literatura, o teórico traça uma viagem no tempo destacando algumas definições da força e do poder da literatura, sua utilidade e pertinência em cada momento da história. Primeiramente, nos é apresentada a definição clássica que é desdobrada a partir de Aristóteles, com a catharsis e a apuração das paixões, ganhando ressonância em Horácio, estendendo-se até o Classicismo: a literatura educa moralmente e instrui deleitando.

Já na segunda metade do século XVIII, outro poder é privilegiado. Com a noção de indivíduo estabelecida, a literatura teria a capacidade de subverter as autoridades, contestá-las, funcionando como um exercício de autonomia e instrumento de reivindicação. Além disso, também nos é apontada a força curativa e atenuadora frente a uma fragmentação da experiência marcante em uma sociedade pós Revolução Industrial.

A terceira força explicitada diverge das que foram expostas anteriormente - a clássica e a romântica. Para esta outra concepção, surgida já no século XX, é próprio da literatura e lhe compete o trabalho de ultrapassagem dos limites da linguagem ordinária, exceder as limitações impostas pela língua, através do jogo e da trapaça, fazendo-a exprimir o inexprimível.

Há ainda um quarto ponto, não propriamente uma força: o crítico vê em uma das concepções mais atuais de literatura uma recusa de qualquer função, nenhuma aplicação social ou moral, senão um exercício sobre si mesma. 
Após traçar esses poderes atribuídos à literatura ao logo do tempo e buscar uma convergência, uma harmonia entre eles, Compagnon constrói um elogio da literatura, respondendo à sua pergunta Literatura pra quê?

Sabendo que "a literatura não é mais o modo de aquisição privilegiado de uma consciência histórica, estética e moral” (COMPAGNON, 2009, p. 57), o teórico vai ressaltar sua singularidade frente a outras formas que com ela rivalizam ao falar do e para o homem, além de deixar claro seu papel fundamental na formação humana.

O próprio da literatura é a análise das relações sempre particulares que reúnem as crenças, as emoções, a imaginação e a ação, o que faz com que ela encerre um saber insubstituível, circunstanciado e não resumível sobre a natureza humana, um saber de singularidades. (COMPAGNON, 2009, p. 59; grifo nosso)

De acordo com Compagnon, a literatura, por apresentar um exercício de pensamento perene, dotado de uma duração incalculável e, por ser fornecedora de trocas e agenciadora de experimentações dos (im)possíveis, deve ter seu lugar defendido, mantido e assegurado.

Compreendidas tais características que vimos ser apresentadas por Compagnon e Italo Calvino, levantamos a nossa pergunta: como e qual é o papel/função da crítica ao se deparar com um objeto de tamanha riqueza e potencialidades como a literatura?

É em busca não de uma resposta plena, mas de uma proposta que nos mantenha instigados a manusear, trabalhar, atravessar e se deixar atravessar por todas as pulsações que uma obra literária nos fornece, que nos dispomos neste artigo.

\section{O CRÍTICO-ARTISTA}

Em Pelo colorido para além do cinzento (quase um manifesto), de Alberto Pucheu, temos o seguinte diagnóstico: a crítica literária se apresenta há muito tempo completamente separada da literatura - objeto abordado por ela. De acordo com o autor, isso se daria por conta da crítica pretender certa imparcialidade, um distanciamento frio, desconsiderando toda uma relação mais intensa entre crítico e texto, toda uma relação afetiva existente entre esses dois componentes. É exatamente na busca por essa objetividade que se situa um grande problema: um engessamento, impossibilitando que as forças do texto e do crítico se encontrem e se realizem como um novo texto. Nesse caso, o que ocorre é a manutenção de uma "faixa de segregação entre literatura e crítica, entre poesia e teoria" (PUCHEU, 2007, p. 15). De um lado, temos os especialistas que apenas desmontam e demonstram, falando apenas sobre o texto, com toda a sobriedade exigida por uma disciplina objetivista. De outro, o texto com sua potência, suas entradas e saídas, que não só permitem como pedem, clamam por uma leitura potente, que seja feita não sobre, mas consigo e por sobre si. Dentro de tal cenário, a crítica aborda seu objeto "sem deixar a intensidade do modo poético emergir em seu próprio fazer" (PUCHEU, 2007, p. 12). Como solução,

seria preciso a transformação do leitor-crítico em leitor-criador ou em escritor-intensivo, que buscasse janelas por onde sair do texto, elevando sua carga suplementar a tal nível que, mantendo ou não o foco no texto abordado, borrasse cada vez mais o que antes era considerado discurso 
primeiro, ou seja, ainda que falando sobre outro, falasse, sobretudo por sobre outro. (PUCHEU, 2007 p. 16)

O que vemos é um chamado para que se tenha um crítico-artista que, em vez de simples e objetivamente falar sobre o outro, no esquema de desmontar e demonstrar, com a pretensão de uma explicação totalizante, fale por sobre, que apresente um novo, que seja capaz de dizer o que o texto ainda não disse e fazê-lo falar aquilo que potencialmente ele pode dizer. O que se quer é "introduzir um original, um sobre-sentido, um sobrescrito" (PUCHEU, 2007, p. 16). O que se quer é uma rasura, um movimento de leveza-rapidez que forje, a pacientes marteladas, um novo texto a partir de outro, deixando o primeiro intacto, pronto para uma nova investida.

Cabe ao intérprete, ao crítico, uma criação que não se apropriar da obra de que está falando, mas, ao contrário, resguardá-la em uma zona inacessível através da inventividade crítica. (PUCHEU, 2012, p. 90-91)

Nesse caso, é bom trazermos a leitura que Rosa dias faz do o pensamento de Nietzsche: "interpretar não é explicá-lo, não é transportá-lo de uma linguagem para outra linguagem como se a primeira fosse referência para segunda; ao contrário, é essa que dará uma nova forma um novo conteúdo à primeira" (DIAS, 2001, p. 30).

Em tal pensamento, a interpretação aparece como uma recriação. Portanto, o crítico-artista deve interpretar neste sentido: o de uma apropriação para uma recriação. Para ser um crítico-artista, é preciso antes ser um leitor-artista, fazer com que aquele que seria meramente um guia se torne um aliado na criação.

\section{O LEITOR-ARTISTA}

A interpretação exige, por parte do leitor, certa disponibilidade: que o leitor se permita a ser afetado para que seja realizado, através de si, o transporte de afetos do texto literário para o texto crítico. Nesse caso, a leitura surge como uma reescritura, pois "não há leitura sem reescritura, sem uma recriação, que nada mais é que a doação de uma nova forma, uma reconfiguração de um novo estilo" (DIAS, 2001, p. 30).

Dentro dessa perspectiva, existe um jogo de forças entre texto e leitor, podendo o leitor apropriar-se de um texto, dando a ele nova significação. Com isso, leitor e texto estabelecem uma relação de afinidade.

Dentro de sua linguagem fisiológica, Nietzsche nos traz outro ponto relativo à interpretação: "ruminar não é uma elucubração da consciência, nem uma combinação de conceitos. É uma atividade que nos permite refazer a experiência do autor, apropriar-se de seu pensamento e assimilá-lo" (DIAS, 2001, p. 31).

Para que se recrie, dentro do jogo de forças que é a interpretação, é necessário lentamente assimilar o pensamento do outro e, "ao assimilar, transformar em sangue próprio o sangue alheio, fazemos confluir todo o passado para o presente" (DIAS, 2001, p. 32).

De acordo com esse pensamento, a leitura deve ser lenta e despreocupada, sem que se espere algo em troca, para saber selecionar, para assimilar e digerir. 
Outro ponto pertinente é o fato de saber esquecer, que, para Nietzsche, está diretamente ligado às forças ativas e criadoras.

A todo agir liga-se um esquecer: assim como a vida de tudo o que é orgânico diz respeito não apenas à luz, mas também à obscuridade. Um homem que quisesse sempre sentir apenas historicamente seria semelhante ao que se obrigasse a abster-se de dormir ou ao animal que tivesse de viver apenas de ruminação e ruminação sempre repetida. Portanto: é possível viver quase sem lembrança, sim, e viver feliz assim, como mostra o animal; mas é absolutamente impossível viver, em geral sem esquecimento. (NIETZSCHE, 2003, p. 9-10)

Para o pensador, memória e história em demasia são extremamente prejudiciais, gerando um homem ressentido, passivo e comportando-se sempre como vítima, o que impossibilita a ação e a criação.

Nietzsche define a faculdade do esquecimento - que para ele tem caráter positivo e ativo - como uma faculdade de inibição ativa que permite a assimilação psíquica e a digestão de toda a experiência. (DIAS, 2001, p. 79)

A leitura é, portanto, um ato de digestão e esquecimento. Nesse ato, é necessário lentidão, paciência para separar o que nos compõe, para que se assimile o texto. "O importante é assimilar o que o texto tem de força, o que tem de alado e dançarino" (LARROSA, 2002, p. 23). O leitor que esquece é o leitor que digere e que permite que o processo dessa digestão o possibilite sair do texto e recriar. "Ler bem é comer bem" (LARROSA, 2002, p. 34).

Continuando dentro do pensamento de Nietzsche acerca da leitura, temos que o exercício da leitura se dá através da multiplicação de perspectivas, que aumentaria as formas afetivas de olhar para o texto, possibilitando uma paixão mais forte para com o texto. A leitura nesse sentido implica algo como "achar, encontrar e roubar, ao invés de regular reconhecer e julgar" (DELEUZE, 1998, p. 16). Essa postura de achar, encontrar e roubar, pode ser lida em a Gaia Ciência, sob o título de Divisa do violento "Nunca pedir! Nada de lamúrias!/Simplesmente pegar, sempre pegar!" (NIETZSCHE, 2001, p. 25).

Desse modo, a leitura artística não quer regular, reconhecer, julgar, explicar, ela não está na ordem do ter de ser feito, ela quer justamente o oposto, como o encontrar, o roubar e o trapacear. É o encontro, o roubo e a trapaça que são capazes de gerar novas significações. Para conseguir esse encontro e, que ele seja proveitoso, é preciso facilitálo, mantendo os sentidos aguçados. O leitor deve se comportar como um aventureiro, "aquele que rejeita os caminhos seguros e conhecidos" (LARROSA, 2002, p. 42). O leitor deve se deslocar e, uma vez em um labirinto, explorá-lo, em vez de procurar uma saída.

Em todas essas propostas temos um leitor ativo que interage com o texto, que é afetado por esse texto. Um leitor disponível para receber o texto, deixando-o fazer parte de sua composição, deixando-o confundir-se com o texto. É um leitor potente, que ao cair no texto, permite-se perambular em seus labirintos, contemplando deliciosamente o caminho, sem procurar de imediato uma saída. É uma relação de amor entre leitor e texto. Obviamente não são todos os textos que acolhem o leitor e o proporcione tais sensações. 
Existem textos que impossibilitam essa leitura, não a convocam, não a atraem para esse relacionamento amoroso.

Apontamos nesta parte o primeiro caminho para que se tenha uma crítica- artística: a postura de um leitor artista. Vimos um modelo de comportamento desse tipo de leitor: qual seria a relação entre esse leitor e o texto. A seguir buscaremos indicar o que seria a escrita artística.

\section{A ESCRITA ARTÍSTICA}

Um segundo fator aparece para sustentar a crítica artística: a escrita artística. Tal escrita só pode surgir após a referida leitura artística. Essa leitura só surge em textos que a proporcionam. Para realizar essa escrita temos de ressaltar mais uma vez a postura do leitor.

Quando um leitor deseja escrever sobre uma experiência de leitura que o afetou, seu estatuto não será de paciente (afetando-se) nem de agente (escrevendo), mas de experienciador, um terceiro lugar que alia recepção do acontecimento a seu encaminhamento. Deleuze chamou esta operação de contraefetuação. (CORRÊA, 2004, p. 120)

Nesse sentido, continuamos na relação leitor-texto. Determinados textos pedem para ser contraefetuados. É assim, após experienciar, que um leitor afetado parte para a crítica que se pretende forte.

Com relação ao ato de escrever em si, essa crítica não pretende apenas uma valoração, um julgamento do texto literário, ela pretende ser uma abordagem do texto e que seja ao mesmo tempo literária. Não se quer uma crítica meramente instrumental que demonstre ou transmita uma obra anterior externa a si. O que se pretende não é "a substituição deste por aquele nem o apagamento daquele por este" (PUCHEU, 2012, p. 87). Mais uma vez retornamos à questão de que não se trata de se escrever sobre um texto, mas com o texto, tê-lo como companheiro, não como simples guia.

Para isso, seria necessário ser um escritor no sentido forte dessa palavra-função. Fica a pergunta: como se comportaria esse escritor? Entendemos que seria um escritor que faz da escrita algo inseparável do devir. É na busca de uma escrita inseparável do devir que a crítica pode se tornar artística, pois na concepção de Deleuze, a literatura forte é inseparável do devir, por estar ao lado do inacabado, do informe e seus atravessamentos.

Devir não é atingir uma forma (identificação, imitação, Mimese), mas encontrar a zona de vizinhança, de indiscernibilidade ou de indiferenciação. (DELEUZE, 1997, p. 11)

A escrita como devir é o que o crítico-artísta almeja. Uma escrita que seja mobilizadora e reinventora dos (im)possíveis. Como a matéria da escrita é a língua, é ela que deve ser trabalhada.

Deleuze defende a existência de várias línguas numa mesma língua, com as quais o escritor poderá criar a sua ao desequilibrar a língua padrão, dominante, desestabilizar as formações linguísticas canônicas. (MACHADO, 2009, p. 207) 
Para Deleuze, estilo é uma variação da sintaxe, uma estratégia que permite que o escritor crie uma língua estrangeira dentro de sua própria língua. Ter um estilo significa criar uma língua para si, forjar uma língua para si. E o estilo, como essa outra língua, essa outra sintaxe que possibilita que o escritor produza um devir-outro da língua, um "delírio" que a faz sair dos eixos, dos trilhos, que a faz escapar do sistema dominante (MACHADO, 2009, p. 207).

Nesse sentido, o escritor é responsável por desorganizar a língua, inventando uma nova no interior da primeira. Ele cria novas estruturas sintáticas e gramaticais, produz uma diferença ao fazer a linguagem variar.

Fazer a língua gaguejar também é um procedimento de estilo que cria uma língua estrangeira na língua materna. "Conseguir gaguejar em sua própria língua, é isso um estilo" (DELEUZE, 1998, p. 12). No entanto, a gagueira aqui referida é uma "gagueira da linguagem, não uma gagueira da fala" (MACHADO, 2009, p. 209), é uma gagueira no nível da langue, que cria palavras novas. Com isso, temos uma linguagem intensiva sempre desequilibrando o funcionamento do sistema, deixando-o em variação contínua, aberto a perplexidades e estranhezas.

Tal procedimento se apresenta como um bilinguismo em uma mesma língua. $\mathrm{O}$ que nossa proposta de escrita quer é exatamente isso. Então o imperativo é este: "devemos ser bilíngues mesmo em uma única língua, devemos ter uma língua menor no interior de nossa língua, devemos fazer de nossa própria língua um uso menor" (DELEUZE, 1998, p. 12).

Trata-se de um bilinguismo que afeta o sistema, que não o deixa ser homogêneo, proporcionando linhas de fuga, ao inventar um uso menor da língua, fazendo a língua deslizar e desequilibrar-se variando incessantemente, excedendo suas possibilidades. Podemos resumir essa postura da seguinte forma: "um grande escritor sempre se encontra como um estrangeiro na língua em que se exprime, mesmo quando é sua língua natal. No limite, ele toma suas forças numa minoria muda desconhecida que só a ele pertence" (DELEUZE, 1997, p. 124).

Esse bilinguismo não é uma mistura de outra língua à língua do escritor, mas sim a inserção de uma língua não preexistente dentro dessa língua. Isso faz com que a língua grite, dobre sobre si mesma, tropece e escape do caminho previamente traçado por um sistema fechado.

Ainda dentro da perspectiva de escrita artística, mais uma vez trazemos o pensamento de Nietzsche, com sua concepção trágica a respeito da arte. Para o autor de Zaratustra, a "arte não cura, não acalma, não sublima, não compensa, não 'suspende' o desejo o instinto e a vontade" (DELEUZE, 1976, p. 68). A arte aparece como um estimulante da vontade de potência. Não se trata de uma concepção da arte como reativa, mas ao contrário, de uma concepção ativa, que relaciona suas forças com a vontade de potência para que ela se apresente como afirmação. Assim, a escrita como arte deve excitar a vontade de potência, estimulá-la para que seja afirmação das forças ativas. Tudo para se inventar novas possibilidades de vida, libertar a vida de onde ela se encontra presa. A vontade potência, configurada como afirmação das forças ativas, propicia o criar, qualidade própria da arte. Dessa forma, os textos de escrita crítica que se pretendem artísticos devem se abrir para essa força criadora, que é a fonte de onde se emana e se produz constantemente vida. Com tal procedimento, é possível tocar a vida do mesmo 
modo que as obras que eles abordam conseguem, tornando-se assim tão potentes quanto elas. Assim, a crítica passa a carregar uma conjunção mais forte entre o teórico e o poético. Tal conjunção entra naquilo que Deleuze chama de núpcias entre reinos, um dos aspectos do devir, que se configura como uma dupla captura, não sendo um imitar nem um fazer como, mas algo que está no meio que brota pelo meio.

Encontramos mais uma reflexão acerca do escrever em Pensamento, Corpo $e$ Devir. Uma Perspectiva Ético/Estético/Política no Trabalho Acadêmico, de Suely Rolnik. Nesse texto, temos a defesa de um procedimento de escrita que seja um produto daquilo que ela chama de marcas. Definidas como "estados inéditos que se produzem em nosso corpo, a partir das composições que vamos vivendo" (ROLNIK, 1993, p. 242), tais marcas instauram diferenças que contribuem para a criação de um novo corpo. Cada marca, quando encontra alguma ressonância, produz uma nova diferença e, portanto, um novo corpo.

E assim vamos nos criando, engendrados por pontos de vista que não são nossos enquanto sujeitos mas das marcas, daquilo que em nós se produz nas incessantes conexões que vamos fazendo. Em outras palavras, o sujeito engendra-se no devir: não é ele que conduz, mas sim as marcas. (ROLNIK, 1993, p. 242)

Dessa forma, cabe ao sujeito abrir-se ao estranhamento causado pelo que as marcas fazem em seu corpo, não só para aprender a lidar com elas, mas também para aumentar a potência com que a vida se afirma. No entanto, para isso não há uma regra, um método. Só se aprende a lidar com elas através delas mesmas. É um aprendizado infinito que se encerra apenas com a morte.

A escrita, como dissemos, é tida como um produto dessas marcas. Assim, nos deparamos com duas possibilidades. Uma delas é a produção de um texto que apresenta um brilho puramente intelectual, sem presença de uma vitalidade que vibra e comunica possibilidades. Isso ocorre quando o sujeito se perde das marcas, ou não consegue suportar o estranhamento causado por elas. Outra possibilidade é o sujeito obedecer às marcas, deixar-se estranhar para produzir um texto pleno, um texto reluzente, cheio de vida. Apesar de não haver uma regra ou um método para se conseguir essa escrita, é necessário certo rigor, um rigor ético, estético e político. Ético seria o rigor com que nos atentamos ao modo como somos afetados pelas diferenças, como as marcas nos conduzem e exigem. Estético por um rigor relativo à criação, criação que traz as marcas consigo. Político por ser o rigor de "uma luta contra as forças em nós que obstruem as nascentes do devir" (ROLNIK, 1993, p. 245).

Uma escrita artística, dentro desse pensamento, seria uma escrita que se abre, com os referidos rigores, aos estranhamentos causados pelas marcas para se configurar como uma escrita que contenha vitalidade, que agencie experimentações e não apenas uma erudição pesada e paralisante com um brilho que só faz cegar.

Após tudo o que foi dito com relação ao escrever artisticamente, o que impediria a crítica de adotar tal prática de escrita? 


\section{A ESCRITA ACADÊMICA}

Um dos principais aspectos que contribuem para que a escrita crítica se distancie de seu objeto foi dito no início desse trabalho: a pretensa postura objetivista e imparcial, o distanciamento do crítico para com o objeto que aborda, lançando mão da cientificidade para falar sobre ele.

Boa parte dessa condição pode ser creditada à academia. Tal crédito é dado, principalmente, por ser a academia o lugar de formação dos críticos. É nela que se prolifera o discurso da cientificidade, discurso que coloca a postura fria e objetiva como um como fator primordial para examinar, avaliar, etc. Roland Barthes diz que, ao seguir esse discurso, fica-se restrito ao código convencional, contribuindo para um engessamento do pensamento.

Em nossa sociedade, em nossas instituições, o que se pede ao estudante, ao jovem pesquisador, ao trabalhador intelectual, nunca é seu desejo: não se lhe pede para escrever, pede-se para falar (ao longo de inúmeras exposições) ou para "relatar" (em vista de controles reguladores). (BARTHES, 1988, p. 97)

Isso, de certa forma, colabora para que a escrita se enfraqueça, pois, uma vez que aquilo que é exigido é o combatido falar sobre, deixa-se de lado a possibilidade de falar com o objeto, através de afetos, intensidades e experimentações. Ou seja, tudo que vise um descentramento, uma leveza-rapidez que crie um escape, que tenha o objetivo de "tratar a escrita como um fluxo, não como um código" (DELEUZE, 1992, p. 15) é desconsiderado, tornando a escrita crítica esvaziada em nome de uma análise pesada, lenta e modorrenta, elementos completamente díspares da literatura.

\section{CONCLUSÃO (CAMINHOS POSSÍVEIS)}

Não existe uma saída clara e marcada que solucione essa situação que cria uma crítica engessada, distante de seu objeto de abordagem, mas há formas de trapacear. Trapacear é preciso. A trapaça salutar própria da literatura, trapaça "que permite ouvir a língua fora do poder" (BARTHES, 1978, p. 16), trapaça como tática de crítica e transformação. Para isso, é necessária uma reinvenção contínua em todos os aspectos, sempre com investimentos nos pontos desguarnecidos do sistema (sempre há um). Uma vez infiltrado, tornar-se livre para deslizar e dançar, retirar os grilhões que não permitem o vôo, descarregar o corpo, deixando-o leve e rápido. Tudo isso com cuidado para não se perder, para não ser capturado, petrificado pela visão da Medusa e assim transparecer toda força e poder presentes na literatura.

Fechamos com mais duas passagens de Nietzsche em A Gaia Ciência que podem servir como exemplo ao cuidado ético a ser tomado.

"A um amigo da luz"

Não querendo cansar a vista,

Persiga o sol pela sombra. (2001, p. 23) 


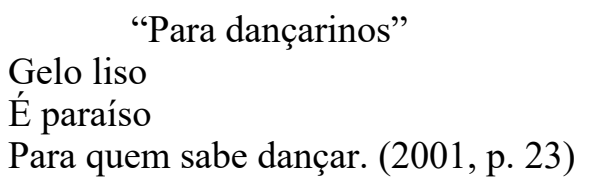

\section{REFERÊNCIAS}

BARTHES, R. Jovens Pesquisadores. Em: O Rumor da língua. Trad. Bras. São Paulo: Brasiliense, 1988. p. 96-102. . Aula. Trad. Bras. São Paulo: Cultrix, 1978.

CALVINO, I. Seis propostas para o próximo milênio: lições americanas. Trad. Bras. São Paulo: Companhia das Letras, 1990.

COPAGNON, A. Literatura para que? Trad. Bras. Belo Horizonte: Ed. da UFMG, 2009.

CORRÊA, M. O Liso do Sussuarão-convergências entre a filosofia de Deleuze e a ficção de Rosa. Ipotesi, Juiz de Fora, v. 8, n.1 e 2, 119-130, 2004.

DELEUZE, G. A literatura e a vida. Em: Critica e clínica. Trad. Bras. São Paulo: Ed. 34, 1997. . Gaguejou... Em: Crítica e clínica. Trad. Bras. São Paulo: Ed. 34, 1997. p. 122-129. Carta a um crítico severo. Em: Conversações. Trad. Bras. São Paulo: Ed. 34, 1992.

Nietzsche e a filosofia. Trad. Bras. Rio de Janeiro: Editora Rio, 1976.

; PARNET, C. Uma conversa, o que é, para que serve? Em: Diálogos. Trad. Bras. São Paulo: Editora Escuta, 1998. p. 9-45.

DIAS, R. Nietzsche, vida como obra de arte. Rio de Janeiro: Civilização Brasileira, 2001.

LARROSA, J. Nietzsche e a educação. Trad. Bras. Belo Horizonte: Autêntica, 2002.

MACHADO, R. A linguagem literária e o de fora. Em: Deleuze, a arte e a filosofia. Rio de Janeiro: Zahar, 2009. p. 206-221.

NIETZSCHE, F. Segunda consideração intempestiva: da utilidade e desvantagem da história para a vida. Trad. Bras. Rio de Janeiro: Relume Dumará, 2003.

. A gaia ciência. Trad. Bras. São Paulo: Companhia das Letras, 2001.

PUCHEU, A. Deleuze e Baudelaire: o monstro crítico. Em: FERREIRA, R. de S.S.; PEREIRA, T.M.S. (Orgs). Literatura e Política. Juiz de Fora: Ed. da UFJF, 2012. p. 85-93.

. Pelo colorido para além do cinzento (quase um manifesto). Em: Pelo colorido para além

do cinzento (a literatura e seus contornos interventivos). Rio de Janeiro: Azougue Editorial, 2007. ROLNIK, S. Pensamento, corpo e devir: uma perspectiva ético, estético, política no trabalho acadêmico. Cadernos de Subjetividade, São Paulo, n. 2, 241-251, 1993.

Artigo recebido em: fevereiro de 2018.

Aprovado e revisado em: agosto de 2018.

Publicado em: dezembro de 2018.

Para citar este texto:

FAULHABER, Gabriel Moreira. Por uma crítica artística. Entremeios [Revista de Estudos do Discurso, ISSN 2179-3514, on-line, www.entremeios.inf.br], Seção Temática [Discurso, arte e literatura - Parte II], Programa de Pós-Graduação em Ciências da Linguagem (PPGCL), Universidade do Vale do Sapucaí (UNIVÁS), Pouso Alegre (MG), vol. 17, p. 235-245, jul. - dez. 2018.

DOI: http://dx.doi.org/10.20337/ISSN2179-3514revistaENTREMEIOSvol17pagina235a245
} 